\title{
Escuela y poder: un enfoque contestatario
}

Rodolfo Meoño Soto ${ }^{1}$

\section{Introducción}

Con la aparición en los países altamente industrializados de un movimiento juvenil de carácter contestatario al liamado proceso de globalización de la economía de mercado, se ha retomado en los círculos intelectuales el interés por la Pedagogía Crítica norteamericana. El propósito del presente ensayo es, entonces, la auscultación de las teorías críticas fundacionales de dichas corriente pedagógica en Norteamérica, desarrolladas por Henry Giroux, estadounidense, y Peter McLaren, de origen canadiense.

Como ha de evidenciarse, tanto Giroux como McLaren tienen sus propias preocupaciones y constituyen sus propias categorías, lo cual obviamente conduce a pensamientos claramente diferenciados. Sin embargo, ambos son

Filósofo y pedagogo costarricense 
asiduos colaboradores, tanto entre sí como con los teóricos que también construyen una Pedagogía Crítica en otras latitudes; en particular, en América Latina, en Inglaterra y en España. Pero, además, como un elemento inherente a la teoría crítica, son cómplices en lo que asumen como un compromiso político y ético insoslayable: la construcción y difusión de una política cultural contestataria, la cual promueve una sociedad equitativa, justa y tolerante de las diferencias.

Para efectos analíticos, en el presente ensayo se recurre a la sistematización de la Pedagogía Crítica norteamericana a partir de sus fuentes fundacionales, a saber, la obra histórica Los profesores como intelectuales, de Giroux, y la controvertida obra Pedagogía Crítica y cultura depredadora, de McLaren.

Teniendo en consideración la doble naturaleza de la teoría crítica, como modelo interpretativo y como instrumento de cambio, en primera instancia se analizan ambos autores en lo concerniente a la concepción de la propia Pedagogía Crítica y su capacidad hermenéutica en relación con el fenómeno educativo; para mostrar, posteriormente, sus renovadoras propuestas de un currículo alternativo, coherente con la política cultural que promueve el cambio social.

\section{La concepción de la Pedagogía Crítica}

El punto de partida de Herny Giroux, reside en el cuestionamiento del carácter ideológicamente neutral del desarrollo curricular; el cual ha conducido al predominio de una visión tecnocrática en la construcción del currículo escolar que lo aliena de la concepción de un pretendido conocimiento curricular objetivo, el cual intenta sustentar el enfoque positivista; para tales propósitos, la Pedagogía 
Crítica debe develar con claridad meridiana los procesos de construcción social del conocimiento y evidenciar los mecanismos de negociación del significado en el aula.

El enfoque crítico entiende la educación como un proceso dinámico guiado por una cierta racionalidad social, la cual comprende una serie de valores, actitudes de patrones de comportamiento. Así se dirime, a manera de ejemplo, lo que es aceptable o no, lo que es deseable, lo que es o no es moral, lo que es valioso o lo que es o no útil.

No en vano, para Giroux:

Educadores y padres deben tomar conciencia del hecho que el conocimiento no es neutral ni objetivo, sino más bien una construcción social que encarna determinados intereses y supuestos. El conocimiento debe ponerse en relación con el tema del poder, lo que sugiere que educadores y demás personas implicadas en la escuela han de plantear cuestiones acerca de las pretensiones de verdad del conocimiento en cuestión. (p. 47)

Como resultado del punto de partida anteriormente enunciado, el enfoque crítico en la Pedagogía indaga y cuestiona las interconexiones entre la racionalidad dominante y la escuela, entendiendo al centro educativo como una institución de reproducción social. Goroux indica que tanto el trabajo como la familia, la religión y la educación, tienen la función de servir como inductores y filtros de las estructuras económicas y políticas para el establecimiento de valores, actitudes y pautas de comportamiento. Por ende, señala que es necesario comprender el carácter político de la función educativa; en la cual sus protagonistas sustentan o adversan las diversas configuraciones de fuerzas sociopolíticas que legitiman o combaten los intereses económicos y políticos dominantes. 
Una visión crítica del conocimiento escolar sería muy distinta de una visión tradicional de ese mismo conocimiento: El conocimiento crítico haría tomar conciencia a los estudiantes, lo mismo que a los profesores, y en relación con su status de su condición de grupo ubicado dentro de una sociedad con relaciones específicas de dominación y subordinación (pp. 47-48).

La racionalidad dominante moldea las expectativas y los deseos de los individuos y otorga inteligibilidad a las experiencias. Por ende, determina el marco de referencia de la educación: qué debe estar presente (cuáles preguntas cabe hacerse), y cuál es el límite de lo posible (en qué se es omiso).

A pesar de compartir con otros críticos de la educación respecto a la noción de socialización y sus mecanismos en la escuela. Giroux plantea que la Pedagogía Crítica no puede omitir el abordaje de la relación entre ideología y poder y el uso del conocimiento y el poder en la organización educativa y en la práctica propia del salón de clases.

Sobre la base anterior, Giroux plantea el concepto de capital cultural, el cual a diferencia del capital material (distribución de bienes y servicios), se entiende la siguiente manera:

El concepto de capital cultural representa además determinadas maneras de hablar, actuar, moverse, vestirse y socializarse que son institucionalizadas por las escuelas. Éstas no son meros lugares donde se imparte instrucción, sino también lugares donde se aprende la cultura de la sociedad dominante y donde los estudiantes experimentan la diferencia existente entre los status y distinciones de clase, que de hecho se dan en el conjunto de la sociedad. (p. 45) 
Según el criterio de Giroux, el enfoque de la escuela como una agencia de socialización para la reproducción económica y cultural, constituye una herramienta analítica incompleta para investigar profundamente las funciones sociales en la escolarización. Se buscaría, más bien, revelar la sociedad a partir de la socialización: de los supuestos y las prácticas escolares.

En Giroux, la Pedagogía Crítica desnuda la inocencia de la escuela, lo que él llamó anteriormente en Teoría y resistencia en educación, el dogma de la percepción inmaculada. La educación no es un proceso neutral, política o culturalmente. Lo que cabe preguntarse es cómo funciona el poder tanto en el orden social como en la escuela.

Pero, más allá del reconstruccionismo social o de los análisis de las izquierdas, los teóricos radicales, como Giroux se clasifica, entienden las escuelas como sitios complejos, los cuales pueden ser agentes de reproducción social y cultural o bien espacios de contestación y lucha contra el status quo. En cada caso, se hace necesario examinar los mecanismos de dominación o de resistencia, los cuales se evidencian, sin lugar a dudas, en el currículo educativo:

Las escuelas son lugares de contestación y lucha y ... como lugares de producción cultural encarnan representaciones y prácticas que constituyen y al mismo tiempo bloquean las posibilidades de una acción humana entre estudiantes (p. 149)

De ahí que Giroux indique el papel alternativo, tal como lo visualizaba Gramsci, que puede jugar el profesor, en su condición de intelectual, en el proceso de reconstrucción social y cultural:

El intelectual es algo más que una persona de letras, o un productor $\mathrm{o}$ transmisor de ideas. Los intelectuales 
son también mediadores, legitimadores y productores de ideas y prácticas sociales. (p. 201)

Por su parte, a diferencia de Giroux, el pensador canadiense McLaren estructura el concepto de Pedagogía Crítica a partir de la noción de cultura depredadora, entendiendo dicha pedagogía como una reflexión y la resistencia creativa ante el fenómeno de una sociedad violenta, descarnada, que promueve la ley de la selva recurriendo a la competitividad antes que a la solidaridad, y a la individualidad antes que al compromiso grupal.

McLaren muestra una gran capacidad premonitoria, al anticipar que la aproximación a la escolarización como una especie de circo contemporáneo, en el cual debe prevalecer la diversión, conduciría a la reproducción en la escuela de la violencia que trasmiten los mass media. Desafortunadamente, McLaren anticipa los asesinatos cruentos e insensatos que los propios jóvenes estadounidenses han provocado en sus centros educativos en diferentes estados de esa nación. A continuación, véase una muestra de dicha capacidad premonitoria, en una obra cuya primera versión en inglés se remonta a 1995:

El futuro tiene un aspecto vacío e inmenso. La película de Oliver Stone, Asesinos natos (Natural Born Dillers, 1994), nos da una idea del "gracioso" Ciudadano Golem que la cultura capitalista está produciendo, y del fabuloso futuro que nos espera en la cultura depredadora. Preparaós profesores para un curriculum agitado. Va a ser real (p. 44).

A partir de dicho concepto de cultura depredadora, McLaren reseña los desarrollos en los últimos quince años de una teoría radical de la educación, la cual surge en 
Norteamérica con la nueva sociología de la educación y de la llamada teoría crítica de la educación. Este análisis histórico le permite diferenciarse de muchos de sus representantes en el mismo sentido en que lo hiciera Giroux. Al igual que este último, McLaren señala las limitaciones que implican el constreñirse a la crítica de la política educativa y el sistema escolar, sin generar una propuesta alternativa:

A pesar de los avances que la pedagogía crítica ha experimentado durante la última década, todavía no se ha resuelto el problema de cómo se define y se desarrolla la política cultural. Este problema proviene de la unilateridad de los análisis de la tradición crítica. La pedagogía crítica no ha conseguido articular una visión tendiente al autofortalecimiento y a la transformación social; consecuentemente, es necesario especificar el significado del término pedagogía crítica con más precisión. (p. 52)

A partir de este punto, McLaren construye su propio arsenal categorial entendiendo la pedagogía critica de la siguiente manera:

La pedagogía crítica, en la acepción utilizada aquí, se refiere a una forma de política cultural dirigida hacia la intensificación y la transformación de la imaginación social... como forma de política cultural intenta reorientar las limitaciones ideológicas de los actuales análisis de la enseñanza y de las principales discusiones en pedagogía, particularmente las que aparecen en los programas de formación del profesorado. Por ejempio, los estudiantes de ciencias de la educación suelen ser introducidos en una concepción unidimensional de la enseñanza: así conciben la enseñanza 
como un conjunto de reglas y de prácticas reguladoras que han sido desprendidas de toda ambigüedad, contradicción, paradoja y resistencia. Las escuelas son presentadas como ajenas a todo conflicto y contestación ideológica. (pp. 53-54).

Para McLaren, la Pedagogía Crítica no conduce sino que, más bien, consiste en un programa de acción política, el cual debe estar orientado en primer término hacia el profesorado, tal como lo visualizaba también Giroux a partir de la obra de Gramsci. La labor política con los profesores busca combatir el lenguaje que legitima los roles del docente y el estatus fáctico de las epistemologías androcéntrica, occidentales y blancas.

La diferencia principal con Giroux radica en que para este último, como se indicara anteriormente, la escuela refleja en su seno la ideología estadounidense dominante como un agente de producción social y cultural; mientras que McLaren va más allá y establece que la escuela no es que refleja a la ideología dominante sino que la constituye. Es en la propia institución educativa en la cual se generan los supuestos y las prácticas que la comprenden:

... la enseñanza no refleja la ideología dominante, sino que la constituye. Es decir, la enseñanza es un aspecto integral (aunque mediatizado) de la ideología dominante y proporciona las prácticas sociales y las limitaciones materiales necesarias para que la ideología haga su trabajo. Una parte de dicho trabajo consiste en disciplinar la conciencia con lenguajes de análisis selectivos y con la reproducción de formas sociales y culturales específicas a través de la pedagogía; también consiste en la construcción de relaciones de dependencia en función de la raza, la clase y el sexo... (p. 55). 
Como puede apreciarse, McLaren enlaza de esa forma su concepto de política cultural con las luchas del movimiento feminista, del antirracismo y de la defensa de las minorías en general. De hecho, su concepto de democracia, el cual debe orientar la acción contestataria, se cimienta no en los principios formales de la representatividad sino en la existencia de una sociedad tolerante con sus minorías y consolidad a partir de las diferencias, y no de su negación violenta como es propio en esta era de globalización.

De ahí que McLaren rescata el concepto del viraje post modernista, como una ruptura con las formas y los contenidos tradicionales; y, en esa medida, como una oportunidad histórica para su política cultural.

\section{Pedagogía Crítica y currículo educativo}

Según Giroux, la selección organización y distribución del conocimiento escolar -es decir, el macrodiseño curricular - así como la disposición de espacio relacional en el aula, imponen significados y prácticas sociales. De ahí se desprende la importancia de la noción que se tenga de la relación entre escolaridad y sociedad, para efectus del planteamiento de estrategias alternativas para el cambio:

Si los estudiantes han de desarrollar una conciencia política, deben empezar teniendo muy claro que la enseñanza escolares es un proceso político, no solo porque contiene un mensaje político o aborda temas políticos de vez en cuando, sino también porque está producida y situada en un conjunto de relaciones sociales y políticas del que no puede abstraerse. (p. 97)

Para Giroux, existen tres modos de racionalidad: la racionalidad técnica o tecnocrácia, la racionalidad 
hermenéutica, y la racionalidad emancipatoria. La primera entiende la escolarización como instrucción, su oferta curricular se centra en las Ciencias Naturales, las cuales ofrecen leyes comprobables, un supuesto objetivismo y predicción; y establece relaciones en el aula en las que impere el control y la certeza. En este modo de racionalidad, propio de la transmisión de la racionalidad dominante, las Ciencias Sociales se diluyen en la Educación Cívica.

La racionalidad técnica es coherente con la ideología estadounidense actual, la cual se caracteriza por una tendencia irreflexiva y antiteórica; por la acumulación de conocimiento de aplicación inmediata; por la falsa objetividad y neutralidad del conocimiento; por el reformismo en los procesos sociales; $y$ por proclamarse una sociedad abierta al mismo tiempo que se ejerce una supremacía de la llamada cultura occidental sobre las demás culturas del planeta.

Dicha racionalidad técnica o tecnocrática es claramente identificada por Giroux, en términos de la teoría y el desarrollo curricular:

La racionalidad tecnocrática (es) característica de la teoría y el diseño del curriculum tradicional. Esta forma de racionalidad ha dominado el campo del currículo desde sus orígenes y podemos encontrarla en diversos matices en la obra de Tyler, Taba, Saylor y Alexander, Beauchamp y otros. (p. 52)

Sin embargo, lo más preocupante para el cambio educativo lo agrega Giroux a continuación:

William F. Pinar sostiene que entre el 85 y el $95 \%$ de quienes trabajan en el campo del currículum comparten una perspectiva vinculada o por lo menos relacionada estrechamente con la racionalidad tecnocrática dominante. (IDEM). 
Por su parte, el modo de racionalidad hermenéutica se orienta hacia una oferta curricular cuyos componentes tengan un significado construido y negociado; por ende, genera un espacio de interacción comunicativa y simbólica. Sin embargo, Giroux va más allá de la sociología de la educación estadounidense -la cual representa el modo de racionalidad hermenéutico- para proponer el modo de racionalidad emancipatoria, entendiendo al profesor como mediador entre las conciencias, individual y colectiva, a partir de una postura crítica ante su función y su entorno. Lo anterior significa que es necesario conciliar la conciencia y percepción individuales de la conciencia del condicionamiento social y del potencial personal para formular alternativas y realizar cambios.

En consecuencia, Giroux plantea que:

Los valores y procesos sociales que proporcionan el apoyo teórico de la educación social incluyen el desarrollo en los estudiantes de la estima por el compromiso moral, la solidaridad con el grupo, y la responsabilidad social. Además, debería fomentarse un individualismo no autoritario capaz de encontrar el equilibrio entre la cooperación con el grupo y la conciencia social. (p. 78)

La aseveración anterior muestra un punto de encuentro del pensamiento de Giroux con el propio de McLaren, quien combate también abiertamente los principios de individualidad y competitividad propios de la ideología estadounidense e inculcados asiduamente en el aula y la organización del sistema escolar como tal; los mismos principios que ahora están siendo universalizados como parte del proceso actual de globalización de la cultura dominante. Para McLaren, dichos principios están en la base de la cultura depredadora. 
En McLaren, contrarrestando el individualismo acérrimo, el principio central está en la aceptación de la diferencia:

...la voz estudiantil debe enraizar en una pedagogía que permita a los estudiantes hablar, apreciar y practicar la política emancipadora de la diferencia. Dicha diferencia es más que una función de la tolerancia democrática; es además una condición fundamental para el diálogo crítico y para el desarrollo de las formas de solidaridad enraizadas en los principios de verdad, solidaridad, compromiso con la mejora cualitativa de la libertad humana. (p. 60)

Dicho principio de la diferencia conduce a la afirmación de una pedagogía como política de la experiencia estudiantil. Se asume que el partir de las experiencias vividas permite conocer mejor el nexo entre dicha experiencia y los componentes del lenguaje y de su representación. Este nexo ofrece al estudiante pautas críticas para el análisis de sus propias experiencias, dejando de lado los marcos de referencia sancionados por el establecimiento escolar.

El recurso a las experiencias vividas permite también relativizar la noción de verdad, la posibilidad misma de hablar de algo verdadero independientemente de un marco de referencia social y cultural; entendiendo entonces a la producción discursiva como economía política del poder. En este punto, McLaren se apoya explícitamente en Foucault, de quien afirma lo siguiente:

El análisis de Foucault de la economía política de la verdad y su estudio sobre cómo se organizan y se legitiman los regímenes de la verdad, nos proporciona una base teórica... a partir de la cual se puede 
desarrollar un concepto de práctica pedagógica como forma de política cultural. Los profesores y los intelectuales deben ser considerados en función de sus funciones políticas y sociales en un determinado régimen de verdad. (p. 74)

Sobre los fundamentos descritos, McLaren propone el concepto de multiculturalismo crítico; crítico, para diferenciarlo del multiculturalismo conservador, del liberal y del liberal izquierda. En el caso del multiculturalismo conservador o corporativo, se trata de una visión redentora, propia de una visión de corte colonial que integraba, por ejemplo a los afroamericanos, como esclavos, sirvientes o artistas. En una cruel analogía, podríamos indicar algo similar con algunas visiones o enfoques de la integración de los inmigrantes nicaragüenses en el territorio costarricense.

Por su parte, McLaren diferencia su posición del multiculturalismo liberal en la medida en que éste no va más allá de la pretensión de modificar algunas condiciones ambientales para que las etnias marginadas, por ejemplo en Estados Unidos, puedan competir en condiciones igualitarias en el capitalismo post industrial. McLaren señala que una posición de este tipo no puede ser el núcleo de una pedagogía radical:

Esta visión suele colapsar en un humanismo etnocéntrico y opresivamente universalista en el que las normas legitimadoras que gobiernan la sustancia de la ciudadanía son identificadas fuertemente con las comunidades cultural-políticas angloamericanas. (p. 153)

Por su parte, el multiculturalismo liberal de izquierda, a diferencia del anterior que parte de la igualdad de etnias, propone asumir las diferencias, planteando que la 
insistencia liberar en la igualdad de las razas conduce a ignorar las diferencias que hacen relevante a cada una de ellas. En este caso, para McLaren, el problema reside en la esencialización de las diferencias, ignorando el carácter de construcción histórica y social que necesariamente guarda cada idiosincrasia.

El multiculturalismo crítico no asume a la diversidad como una meta, sino que indica que la afirmación y el reconocimiento de la diversidad forma parte de una política cultural comprometida con la justicia social:

La diferencia siempre es un producto de la historia, la cultura, el poder y la ideología. Las diferencias se dan siempre entre grupos y deben ser entendidas en función de la especificidad de su producción. El multiculturalismo crítico se cuestiona la construcción de la diferencia y la identidad en relación con la política radical. Se posesiona en contra del cuento neoimperial de etnicidad monolingüe en la experiencia de una Norteamérica compartida o común que se asocia con las corrientes conservadora y liberal del multiculturalismo. (pp. 155-156)

Más aun, McLaren agrega a lo anterior el planteamiento de la inseguridad e inestabilidad de las relaciones entre significantes y significados:

El lenguaje y el pensamiento occidental son construidos como un sistema de diferencias organizadas de facto $y$ de jure como oposiciones binarias -blanco/negro, bueno/malo, normal/desviado, etc. - en las que el primer término es privilegiado y designado como el término definitorio o como la norma del significado cultural, creando una jerarquía dependiente... los signos 
son parte de una lucha ideológica que crea un régimen particular de representación que sirve para legitimar una determinada realidad cultural. (p. 158)

En consecuencia, para McLaren solo tiene significado aquel currículo que se dedique al estudio de la cultura cotidiana, en sus formas más informales, espontáneas y populares; se trata de ver cómo los patrones culturales de poder se implican en la construcción de la subjetividad y la identidad personal. Pero, teniendo en cuenta que la pedagogía atañe no solo a los centros educativos, sino también a todos los espacios culturales.

El otro aspecto cardinal en el currículo tiene que ver con la preeminencia del fortalecimiento personal y social, ante que otras cuestiones de orden epistemológicas o propiamente técnicas o pragmáticas priorizadas por la lógica del mercado. En consecuencia y coincidiendo totalmente con Giroux, McLaren propone los siguiente:

La pedagogía crítica se debe centrar en la cultura popular y desarrollar estrategias curriculares basadas en cómo se forma la subjetividad de los estudiantes dentro de ellas. Si no trabajamos con los estudiantes en esta área de sus vidas les negamos las verdaderas modalidades de subjetividad que dan significado a sus vidas. (p. 100)

\section{De ahí que:}

...la reforma del curriculum significa afirmar las voces de los oprimidos; los profesores han de dar a los marginados y a los débiles una opción preferencial. Del mismo modo, los estudiantes deben ser animados a producir sus propias lecturas de oposición del 
contenido curricular. Y, por último la reforma del curriculum debe reconocer la importancia de potenciar espacios para la multiplicidad de voces en nuestras aulas, y crear una pedagogía dialogante en la que los sujetos vean a los otros como sujetos y no como objetos. (pp. 168-169)

Por otra parte, la Pedagogía Crítica enfatiza una visión curricular centrada en lo histórico, lo cultural y lo discursivo, desde la perspectiva de los materiales y las técnicas de enseñanza. Lo anterior se afirma en contraposición con el proyecto moderno de ilustración, propio del positivismo debilitado. Se trata de un modelo de razón instrumental y de control burocrático, el cual es adversado totalmente por la Pedagogía Crítica.

Finalmente, podemos distinguir dos tipos de modelos categoriales que emplean Giroux y McLaren, los cuales permiten analizar los componentes curriculares desde una perspectiva crítica. En el caso de Giroux, cabe señalar la distinción que establece entre diferentes racionalidades: tecnocrática, hermenéutica y de emancipación; categorías que permiten diferenciar las diversas ofertas curriculares. $Y$, en el caso de McLaren, dicha diferenciación se hace posible a partir de la distinción entre las modalidades de multiculturalismo: conservador, liberal, de izquierda y crítico.

\section{Conclusiones}

Resulta notoria la preocupación general de la Pedagogía Crítica de contrarrestar la visión positivista de un currículo neutral, fundado en conocimientos objetivos e inmutables. Los autores examinados concuerdan en asumir como punto de partida el carácter ideológico de los contenidos del currículo, así como en general de las prácticas educativas y de animación sociocultural. 
Desde esta perspectiva, es claro que, en Costa Rica, la agenda educativa no está atendiendo las líneas de acción que propone la Pedagogía Crítica: el diseño curricular sigue siendo visto como una labor técnica; la evaluación de resultados se sigue planteando como el norte de la calidad educativa; la. formación permanente de los educadores es vista meramente como un elemento instrumental y no crítico; no se están atendiendo las nuevas desigualdades que surgen a partir de las nuevas tecnologías de la comunicación y de la información; no se está investigando la formación de la cultura en los grupos subordinados; como tampoco se está forjando un proyecto social más igualitario y democrático a partir del reconocimiento del carácter multiétnico y multicultural de nuestra sociedad.

De lo anterior, se desprende la importancia de la difusión y el debate nacional de la Pedagogía Crítica, la cual puede brindar una luz enteramente nueva al panorama educativo costarricense.

\section{Bibliografía}

CASTELL, M. et al. Nuevas perspectivas críticas en educación. Barcelona Ediciones Paidós, 1994.

GIROUX, H. Los profesores como intelectuales. Hacia una pedagogía critica del aprendizaje. Barcelona: Ediciones Paidós, 1990.

McLAREN, P. Pedagogia Crítica y cultura depredadora. Barcelona: Ediciones Paidós, 1992. 